\title{
Efeito do nível de uréia na dieta sobre o desempenho, a qualidade e o estádio de desenvolvimento embrionário em cabras Alpinas
}

\author{
[Effect of the dietary urea level on performance, quality and embryonic development \\ stage on Alpine goats] \\ N.G. Alves ${ }^{1}$, C.A.A. Torres ${ }^{2}$, M.T. Rodrigues ${ }^{2}$, P.R. Cecon ${ }^{3}$, A.D.F. Santos ${ }^{4}$, \\ L.G.B. Siqueira ${ }^{2}$, L.L. Bitencourt ${ }^{1}$, E.A. Moraes $^{2}$ \\ ${ }^{1}$ Departamento de Zootecnia - UFLA \\ Caixa Postal 3037 \\ 37200-000 - Lavras, MG \\ ${ }^{2}$ Departamento de Zootecnia - UFV - Viçosa, MG \\ ${ }^{3}$ Departamento de Estatística - UFV - Viçosa, MG \\ ${ }^{4}$ Faculdade Pio Décimo - Aracaju, SE
}

\begin{abstract}
RESUMO
Utilizaram-se 22 cabras da raça Alpina, distribuídas aleatoriamente em quatro tratamentos (T): as cabras do $\mathrm{T} 1(\mathrm{n}=5)$ formaram o grupo-controle; as do $\mathrm{T} 2(\mathrm{n}=7)$ receberam $0,73 \%$ de uréia na matéria seca da dieta; as do T3 $(n=4)$ receberam $1,46 \%$ de uréia; e as do $\mathrm{T} 4(\mathrm{n}=6), 2,24 \%$ de uréia. As cabras foram superovuladas e os embriões, coletados entre sete e oito dias após a primeira monta, foram avaliados quanto à qualidade e ao estádio de desenvolvimento. Amostras de sangue para dosagem dos teores de uréia e glicose foram coletadas nos dias do estro e da coleta de embriões. Houve efeito linear crescente do nível de uréia nas dietas sobre o consumo de MS $(\mathrm{kg} / \mathrm{dia})$ e de proteína bruta $(\mathrm{kg} / \mathrm{dia})$. O peso das cabras não diferiu $(\mathrm{P}>0,05)$ entre os tratamentos nem entre as semanas experimentais. Dezoito cabras $(81,8 \%)$ manifestaram estro após a sincronização. A duração do estro e o intervalo da remoção da esponja ao início do estro não foram influenciados $(\mathrm{P}>0,05)$ pelos tratamentos. Quatorze cabras $(77,8 \%)$ responderam à superovulação. $\mathrm{O}$ número de estruturas e de embriões coletados não diferiu $(\mathrm{P}>0,05)$ entre os tratamentos. O número $\left(\hat{\mathrm{Y}}=10,90-11,64^{\mathrm{NS}} \mathrm{U}+4,93^{*} \mathrm{U}^{2} ; \mathrm{R}^{2}=0,67 ; \mathrm{P}<0,10\right)$ e a percentagem $(\hat{\mathrm{Y}}=$ $\left.94,08-39,59^{\mathrm{NS}} \mathrm{U}+18,16^{\star} \mathrm{U}^{2} ; \mathrm{R}^{2}=0,94 ; \mathrm{P}<0,07\right)$ de embriões viáveis, e o número ( $\hat{\mathrm{Y}}=10,83-12,18^{\mathrm{NS}} \mathrm{U}$ $\left.+5,02^{\circ} \mathrm{U}^{2} ; \mathrm{R}^{2}=0,78 ; \mathrm{P}<0,08\right)$ e a percentagem $\left(\hat{\mathrm{Y}}=94,83-52,31^{\mathrm{NS}} \mathrm{U}+21,56^{*} \mathrm{U}^{2} ; \mathrm{R}^{2}=0,90 ; \mathrm{P}<0,05\right) \mathrm{de}$ embriões excelentes e bons apresentaram comportamento quadrático em função do nível de uréia nas dietas. Os teores de uréia e glicose no plasma não foram influenciados $(\mathrm{P}>0,05)$ pelos tratamentos. A uréia pode ser fornecida no nível de $2,24 \%$ na MS da dieta de cabras não lactantes.
\end{abstract}

Palavras-chave: cabra, embrião, glicose, uréia

\begin{abstract}
Twenty-two Alpine goats were allocated at random into four treatments: $0.0 \%$ (T1 - control, $n=5) ; 0.73 \%$ $(T 2, n=7) ; 1.46 \%(T 3, n=4)$ or $2.24 \%(T 4, n=6)$ of urea in the dry matter (DM) of the diet. Embryos collected from 7 to 8 days after mating of superovulated goat were evaluated by quality and development stage. Blood samples for urea and glucose analyses were collected at estrus and at embryos collection day. The $D M(\mathrm{~kg} /$ day) and crude protein ( $\mathrm{kg} /$ day) intake increased linearly in function of dietary urea level. Goat body weights were not affected by treatments out experimental weeks (P>0.05). Eighteen goats $(81.8 \%)$ came in estrus after the synchronization. The estrus length and the interval from sponge removal to the beginning of estrus were not affected $(P>0.05)$ by treatments. Fourteen goats $(77.8 \%)$
\end{abstract}

Recebido em 3 de novembro de 2005

Aceito em 10 de abril de 2007

E-mail: nadja@ufla.br 
were responsive to superovulation protocol. The levels of urea (treatments) did not affect structures and embryo numbers $(P>0.05)$. Number $\left(\hat{Y}=10.90-11.64^{N S} U+4.93^{*} U^{2} ; R^{2}=0.67 ; P<0.10\right)$ and percentage $\left(\hat{Y}=94.08-39.59^{N S} U+18.16^{\star} U^{2} ; R^{2}=0.94 ; P<0.07\right)$ of viable embryos, and number $(\hat{Y}=10.83-$ $\left.12.18^{N S} U+5.02 U^{2} ; R^{2}=0.78 ; P<0.08\right)$ and the percentage $\left(\hat{Y}=94.83-52.31^{N S} U+21.56^{*} U^{2} ; R^{2}=0.90\right.$; $P<0.05)$ of excellent and good embryos were quadraticaly effected by urea dietary level. The treatments did not affect plasma urea and glucose levels $(P>0.05)$. Diets for no nursing goats can be supplied by urea at $2.24 \%$ of DM.

Keywords: goat, embryo, glucose, urea

\section{INTRODUÇ̃̃O}

Estudos têm sugerido que o fornecimento de dietas com elevado nível de proteína bruta (PB) e de proteína degradada no rúmen (PDR) influencia a reprodução, reduzindo a taxa de concepção ao primeiro serviço (Canfield et al., 1990) e resultando em maior número de dias abertos e de serviços por concepção (Jordan e Swanson, 1979) em vacas.

O excesso de PB ou de PDR e o fornecimento de uréia na dieta foram associados ao elevado teor sistêmico de N-uréico em ovelhas (Bishonga et al., 1994) e novilhas (Gath et al., 1999), à alteração da composição iônica da secreção uterina (Jordan et al., 1983) e à redução do pH uterino (Elrod et al., 1993; Elrod e Butler, 1993) em vacas. Elevação dos teores de uréia e amônia no fluido útero-tubárico de ovelhas (McEvoy et al., 1997) e de amônia no fluido folicular de novilhas (Sinclair et al., 2000) também foram observados.

Falhas de fertilização e degeneração de embriões bovinos foram relacionadas ao excesso de PDR na dieta (Blanchard et al., 1990). Em ovelhas, o fornecimento de uréia na dieta ocasionou redução da viabilidade (Bishonga et al., 1994; McEvoy et al., 1997) e do desenvolvimento embrionário (Fahey et al., 2001; Papadopoulos et al., 2001). Sinclair et al. (2000) verificaram que ovócitos coletados de novilhas com elevado teor de amônia plasmática resultaram em reduzido desenvolvimento embrionário in vitro. Da mesma forma, a proporção de ovócitos que se desenvolveram em blastocistos in vitro foi reduzida quando os ovócitos foram maturados em meios com 7,5 mmols/l de uréia (Ocon e Hansen, 2003).

Este estudo teve como objetivo verificar o efeito de níveis crescentes de uréia na MS da dieta sobre o desempenho, o número de estruturas e de embriões coletados, a qualidade e o estádio de desenvolvimento embrionário e os teores de uréia e glicose no plasma de cabras Alpinas.

\section{MATERIAL E MÉTODOS}

O experimento, realizado nos meses de junho e julho de 2003, utilizou 22 cabras da raça Alpina, nulíparas, primíparas e multíparas, não-lactantes, com média de idade de 40,55 $\pm 18,48$ meses, distribuídas aleatoriamente em quatro tratamentos (T). As cabras do T1 $(n=5)$ formaram o grupo-controle; as do T2 $(n=7)$, receberam $0,73 \%$ de uréia na MS da dieta; as do T3 $(n=4), 1,46 \%$ de uréia; e as do T4 $(n=6)$, $2,24 \%$ de uréia.

As dietas à base de silagem de milho e concentrado (Tab. 1) foram calculadas para serem isoenergéticas (1,52 Mcal/kg MS no T1 e $1,54 \mathrm{Mcal} / \mathrm{kg}$ MS no T2, T3 e T4) e isoprotéicas (14\% PB na MS) e conterem 28,8\%; 39,0\%; $49,5 \%$; e $60,8 \%$ da proteína total na forma de nitrogênio não-protéico (NNP) nos tratamentos T1, T2, T3 e T4, respectivamente. As percentagens de NNP advindas da uréia em relação à proteína total da dieta foram $0 \%, 13 \%$, $26 \%$ e $40 \%$ nos tratamentos T1, T2, T3 e T4, respectivamente.

As cabras foram adaptadas de forma gradual às rações com uréia, utilizando-se $0,73 \%$ de uréia na primeira semana no T2; $0,73 \%$ e $1,46 \%$ de uréia na primeira e segunda semanas, respectivamente, no $\mathrm{T} 3$; e $0,73 \% ; 1,46 \%$; e $2,24 \%$ de uréia na primeira, segunda e terceira semanas, respectivamente, no T4. Após o período de adaptação, as dietas foram fornecidas por 81 dias antes do início do experimento. 
Alves et al.

Tabela 1. Composição percentual dos ingredientes utilizados nas dietas experimentais (com base na MS)

\begin{tabular}{lcccc}
\hline Ingrediente & \multicolumn{4}{c}{ Tratamento (\% uréia na MS da dieta) } \\
\cline { 2 - 5 } & 0 & 0,73 & 1,46 & 2,24 \\
\hline Silagem de milho & 81,375 & 75,210 & 72,589 & 69,956 \\
Fubá de milho & - & 10,140 & 16,674 & 23,578 \\
Farelo de soja & 17,625 & 12,920 & 8,280 & 3,274 \\
Uréia & - & 0,730 & 1,456 & 2,240 \\
Calcário calcítico & 1,000 & 1,000 & 1,000 & 0,952 \\
\hline
\end{tabular}

As cabras de um mesmo tratamento foram mantidas em baia coletiva. $\mathrm{O}$ alimento concentrado foi fornecido sobre a silagem, duas vezes ao dia, sendo a quantidade total de alimento oferecido ajustada diariamente para permitir, no mínimo, 5\% de sobras. Água e sal mineral foram fornecidos ad libitum. As sobras de cada baia foram retiradas antes do fornecimento diário do alimento e pesadas, para determinação do consumo. Amostras da silagem fornecida e das sobras foram coletadas diariamente, acondicionadas em sacos plásticos e armazenadas a $-20^{\circ} \mathrm{C}$. Amostras compostas de cada três semanas para a silagem e de cada nove semanas para as sobras do T1, T2, T3 e T4 e amostras do fubá de milho e do farelo de soja utilizados tiveram a composição bromatológica determinada segundo os procedimentos descritos por Silva e Queiroz (2002). A composição bromatológica da silagem de milho, do fubá de milho e do farelo de soja utilizados é apresentada na Tab. 2.

As cabras foram pesadas uma vez por semana, no período da manhã, antes do fornecimento da alimentação.

Tabela 2. Análise bromatológica ${ }^{1}$ dos ingredientes utilizados nas dietas experimentais fornecidas às cabras

\begin{tabular}{|c|c|c|c|}
\hline & Silagem & Fubá de milho & Farelo de soja \\
\hline MS (\%) & 26,58 & 88,26 & 88,81 \\
\hline $\mathrm{MO}^{1}$ & 94,84 & 98,28 & 93,59 \\
\hline $\mathrm{PB}^{1}$ & 6,12 & 8,85 & 49,28 \\
\hline $\mathrm{EE}^{1}$ & 3,80 & 4,13 & 1,30 \\
\hline Lignina $^{1}$ & 4,85 & 1,18 & 2,09 \\
\hline $\mathrm{FDN}^{1}$ & 54,73 & 12,82 & 11,27 \\
\hline $\mathrm{FDA}^{1}$ & 32,26 & 1,92 & 8,81 \\
\hline NIDN ( $\% \mathrm{~N}$ total $)$ & 34,21 & 9,96 & 7,00 \\
\hline NIDA ( $\% \mathrm{~N}$ total) & 17,78 & 4,23 & 2,60 \\
\hline $\mathrm{CHO}^{1}$ & 84,91 & 85,30 & 43,01 \\
\hline $\mathrm{NDT}^{1}$ & 64,47 & 86,98 & 79,44 \\
\hline Cinzas $^{1}$ & 5,16 & 1,72 & 6,41 \\
\hline $\mathrm{Ca}^{1}$ & 0,31 & 0,03 & 0,30 \\
\hline $\mathrm{P}^{1}$ & 0,19 & 0,30 & 0,007 \\
\hline
\end{tabular}

MS: matéria seca, MO: matéria orgânica, PB: proteína bruta, EE: extrato etéreo, FDN: fibra em detergente neutro, FDA: fibra em detergente ácido, NIDN: nitrogênio insolúvel em detergente neutro, NIDA: nitrogênio insolúvel em detergente ácido, CHO: carboidratos totais e NDT: nutrientes digestíveis totais.

As cabras foram sincronizadas e superovuladas segundo os protocolos descritos por Salles et al. (2002) com modificações. O estro foi sincronizado com a inserção de esponja intravaginal impregnada com $60 \mathrm{mg}$ de acetato de medroxiprogesterona $^{1}$ por 11 dias. A superovulação foi realizada com $200 \mathrm{mg}$ de NIH-

${ }^{1}$ Progespon ${ }^{\circledR}$ - Schering-Plough - Cotia, Brasil.
FSH-P $1^{2}$, fracionados em seis doses decrescentes, com intervalo de 12 horas entre aplicações e a partir de 48 horas antes da remoção da esponja. Simultaneamente à primeira aplicação de FSH foram administrados $125 \mu \mathrm{g}$ de cloprostenol sódico ${ }^{3}$, por via intramuscular (IM).

${ }^{2}$ Foltropin- $\mathrm{V}^{\circledR}$ - Vetrepharm - Canadá.

${ }^{3}$ Ciosin $^{\circledR}$ Coopers -Schering-Plough - Cotia, Brasil. 
Setenta e duas horas após a remoção da esponja iniciou-se o tratamento antiluteolítico com flunixin meglumine ${ }^{4}$, na dose de $1,1 \mathrm{mg} / \mathrm{kg} / \mathrm{dia}$, durante três dias consecutivos.

A partir de 12 horas após a retirada das esponjas, as cabras foram observadas quanto à manifestação de estro, duas vezes ao dia, às $7 \mathrm{e}$ às 19 horas, por, no mínimo, 15 minutos cada, com auxílio de rufiões. As cabras em estro foram cobertas por bodes de fertilidade comprovada, a cada 12 horas, até a não aceitação da monta.

Os embriões foram coletados pela técnica transcervical em circuito fechado, entre o sétimo e o oitavo dia do ciclo estral (estro = dia zero). Aproximadamente 24 horas antes do início da coleta de embriões, as cabras receberam uma aplicação de $125 \mu \mathrm{g}$ de cloprostenol sódico ${ }^{3}$, por via IM.

A cérvice uterina foi visualizada com o auxílio de um espéculo vaginal e uma fonte de luz e tracionada com duas pinças de Pozzi em direção ao vestíbulo da vagina. Uma sonda nasogástrica $\mathrm{n}^{\mathrm{o}} 10$ ou 12 foi introduzida através da cérvix e em direção ao lúmen de um dos cornos uterinos. A extremidade livre da sonda foi conectada ao equipo, ao qual foram acoplados o filtro de coleta de embriões e uma seringa de $50 \mathrm{ml}$, para infusão do meio de lavagem - solução-tampão salina fosfato modificada por Whittingham (1971), acrescida de $50 \mu \mathrm{g} / \mathrm{ml}$ de gentamicina e $1,0 \%$ de soro fetal bovino -, a $37^{\circ} \mathrm{C}$. O meio de coleta de embriões foi infundido até que houvesse resistência do corno uterino, aproximadamente $20 \mathrm{ml}$, quando, então, a via de infusão foi fechada e a de comunicação com o filtro foi aberta. Foram utilizados, em média, $200 \mathrm{ml}$ de meio de coleta por corno uterino.

Os embriões coletados foram avaliados ao estereomicroscópio quanto à qualidade, I excelente e V - degenerado, e ao estádio de desenvolvimento (Stringfellow e Seidel, 1999).

Foram coletadas amostras de sangue por punção da veia jugular, em tubos de vidro de coleta a vácuo com anticoagulante EDTA para dosagem de uréia e anticoagulante fluoreto para dosagem de glicose, no dia do estro e no da coleta de embriões. As amostras coletadas antes e

${ }^{4}$ Banamine ${ }^{\circledR}$, Schering Plough - Cotia, Brasil. aproximadamente quatro horas após a alimentação foram centrifugadas a $1.000 \times \mathrm{g}$, durante 15 minutos, para a obtenção de plasma. Este foi armazenado a $-20^{\circ} \mathrm{C}$ até a dosagem dos teores de uréia e glicose, por método colorimétrico-enzimático, utilizando kits comerciais ${ }^{5}$.

Os dados foram analisados pelo programa SAEG (Sistema..., 1997). Os dados relativos ao consumo médio individual de MS e PB, duração do estro, intervalo da remoção da esponja ao início do estro, números de estruturas, de embriões, de embriões viáveis e de embriões excelentes e bons, percentagens de embriões viáveis e de embriões excelentes e bons, e concentrações de uréia e glicose no plasma foram submetidos às análises de variância e de regressão. As variáveis relativas ao estádio de desenvolvimento embrionário foram apresentadas na forma de estatística descritiva. Os dados relativos ao peso dos animais foram analisados por meio da metodologia de superfície de resposta.

\section{RESULTADOS E DISCUSSÃO}

Houve efeito linear crescente da adição de uréia às dietas sobre o consumo médio individual de MS e PB, expressos em kg/dia (Tab. 3). Segundo o NRC (Nutrient..., 1981), a adição de uréia à dieta dos caprinos não deve exceder $1 / 3$ da $\mathrm{PB}$ total ou mais que $50,0 \%$ da $\mathrm{PB}$ do concentrado. Neste estudo, o fornecimento de até $40,0 \%$ da proteína total na forma de uréia resultou em aumento linear no consumo de MS. Da mesma forma, Fernandez et al. (1997) relataram que a uréia pode ser fornecida em quantidades acima das preconizadas pelo NRC (Nutrient..., 1981) sem que o consumo de MS seja reduzido.

Os diferentes níveis de uréia nas dietas não influenciaram o peso vivo das cabras $(\hat{\mathrm{Y}}=56,15$; $\mathrm{P}>0,05)$, semelhante entre tratamentos e constante ao longo das sete semanas experimentais, mostrando que a quantidade de alimento oferecida foi suficiente para atender às exigências de mantença.

${ }^{5}$ Doles Reagentes e Equipamentos para Laboratórios Ltda, Brasil 
Tabela 3. Equações de regressão ajustadas do consumo médio individual de MS e PB, em função do nível de uréia nas dietas

\begin{tabular}{|c|c|c|c|c|}
\hline & Equações ajustadas & $\mathrm{R}^{2}$ & Valor de $\mathrm{P}$ & CV (\%) \\
\hline $\mathrm{MS}^{1}$ & $\hat{\mathrm{Y}}=0,76+0,025^{*} * \mathrm{U}$ & 0,97 & 0,01 & 4 \\
\hline $\mathrm{PB}^{1}$ & $\hat{\mathrm{Y}}=0,11+0,0046^{* * *} \mathrm{U}$ & 0,98 & 0,001 & 3 \\
\hline
\end{tabular}

${ }^{\mathrm{T}} \mathrm{kg}$ /dia; MS: matéria seca; PB: proteína bruta.

Dezoito cabras $(81,8 \%)$ manifestaram estro após a sincronização. A duração do estro e o intervalo da remoção da esponja ao início do estro não foram influenciados $(\mathrm{P}>0,05)$ pelos tratamentos (Tab. 4), sendo representados pelas equações $\hat{Y}=$ 33,23 e $\hat{Y}=40,71$, respectivamente. Fahey et al.
(2001) não verificaram diferença no intervalo da remoção do dispositivo intravaginal impregnado com progesterona e o início do estro entre as ovelhas suplementadas com $50 \mathrm{~g}$ de uréia/dia e as ovelhas do grupo-controle.

Tabela 4. Duração do estro (horas) e intervalo da remoção da esponja ao início do estro (horas), em função do nível de uréia nas dietas, coeficientes de variação (CV) e probabilidade dos efeitos linear (L) e quadrático $(\mathrm{Q})$

\begin{tabular}{|c|c|c|c|c|c|c|c|}
\hline & \multicolumn{4}{|c|}{ Nível de uréia na dieta (\% MS) } & \multirow{2}{*}{$\begin{array}{l}\text { CV } \\
(\%)\end{array}$} & \multicolumn{2}{|c|}{ Valor de $\mathrm{P}$} \\
\hline & 0 & 0,73 & 1,46 & 2,24 & & $\mathrm{~L}$ & Q \\
\hline $\mathrm{DE}(\mathrm{h})$ & $\begin{array}{c}27,06 \pm 17,47 \\
(n=5)\end{array}$ & $\begin{array}{c}40,41 \pm 22,47 \\
(n=6)\end{array}$ & $\begin{array}{c}32,36 \pm 14,99 \\
(n=4)\end{array}$ & $\begin{array}{c}30,35 \pm 0,51 \\
(n=3)\end{array}$ & 53 & $\mathrm{~ns}$ & ns \\
\hline $\operatorname{IEE}(\mathrm{h})$ & $\begin{array}{c}41,22 \pm 7,16 \\
(n=5)\end{array}$ & $\begin{array}{c}40,39 \pm 7,11 \\
(\mathrm{n}=6)\end{array}$ & $\begin{array}{c}42,83 \pm 6,36 \\
(n=4)\end{array}$ & $\begin{array}{c}37,67 \pm 6,86 \\
(n=3)\end{array}$ & 17 & ns & ns \\
\hline
\end{tabular}

DE: duração do estro; IEE: intervalo da remoção da esponja ao início do estro.

ns: não-significativo a $5 \%$ de probabilidade pelo teste $\mathrm{t}$.

Entre parênteses $=$ número de cabras que manifestaram estro em cada tratamento.

As dietas experimentais foram fornecidas por $110,60 \pm 6,19 ; \quad 115,33 \pm 6,25 ; \quad 108,50 \pm 5,45 ; \quad$ e $110,67 \pm 10,60$ dias antes da primeira coleta de embriões nos T1, T2, T3 e T4, respectivamente.

Das 18 cabras que manifestaram estro e foram submetidas à coleta de embriões, uma de cada em T1, T2 e T3 (16,7\%) não produziu estrutura, e outra, em T4 $(5,6 \%)$ produziu um ovócito e foram excluídas das análises subseqüentes. Quatorze cabras $(77,8 \%)$ responderam à superovulação com produção de 135 estruturas, sendo $119(88,2 \%)$ embriões, nove ovócitos $(6,7 \%)$ e sete zonas pelúcidas $(5,2 \%)$.

Cinqüenta (42,0\%), 20 (16,8\%), $32(26,9 \%)$ e 17 $(14,3 \%)$ embriões foram coletados das cabras do T1, T2, T3 e T4, respectivamente. Embora mais embriões tenham sido coletados das cabras do T1 e T3, os números de estruturas e de embriões não foram influenciados $(\mathrm{P}>0,05)$ pelos tratamentos (Tab. 5), sendo representados pelas equações $\hat{\mathrm{Y}}=$ 9,64 e $\hat{\mathrm{Y}}=8,50$, respectivamente.

Tabela 5. Número de estruturas e de embriões coletados, em função do nível de uréia nas dietas, coeficientes de variação (CV) e probabilidade dos efeitos linear (L) e quadrático (Q)

\begin{tabular}{lcccccccc}
\hline & \multicolumn{4}{c}{ Nível de uréia na dieta $(\% \mathrm{MS})$} & $\mathrm{CV}$ & \multicolumn{2}{c}{ Valor de P } \\
\cline { 2 - 4 } & 0 & 0,73 & 1,46 & 2,24 & & $\mathrm{~L}$ & $\mathrm{Q}$ \\
\hline Estruturas & $12,75 \pm 8,96$ & $4,60 \pm 1,51$ & $14,67 \pm 12,01$ & $8,50 \pm 0,71$ & & 76 & $\mathrm{~ns}$ & $\mathrm{~ns}$ \\
Embriões & $12,50 \pm 8,96$ & $4,00 \pm 1,73$ & $10,67 \pm 9,61$ & $8,50 \pm 0,71$ & 78 & ns & ns \\
\hline
\end{tabular}

ns: não-significativo a $5 \%$ de probabilidade pelo teste $\mathrm{t}$.

Em novilhas, Gath et al. (1999) não verificaram efeito do fornecimento de uma dieta-controle e dietas de alta ou baixa energia suplementadas com $250 \mathrm{~g}$ de uréia sobre o número de embriões coletados. Em ovelhas, McEvoy et al. (1997) observaram que o número de embriões coletados não diferiu entre aquelas do grupo-controle e as suplementadas com $15 \mathrm{~g}$ ou $30 \mathrm{~g}$ de uréia/dia. 
Fahey et al. (2001) e Papadopoulos et al. (2001) também não verificaram efeito do fornecimento de $50 \mathrm{~g}$ de uréia/ovelha/dia sobre o número de embriões coletados por doadora.

Ao utilizarem a mesma técnica de coleta deste estudo, em cabras da raça Bôer, Gusmão et al. (2003) verificaram média de 8,4 estruturas/doadora e, em cabras de raça não definida, Salles (2003) citou média de 7,8 estruturas/doadora. Na raça Saanen, Lima-Verde et al. (2003) coletaram, em média, 6,3 embriões/doadora. As médias verificadas neste estudo são pouco superiores às mencionadas na literatura, o que pode estar relacionado ao fato de que apenas as cabras que responderam à superovulação foram incluídas nas análises estatísticas.

No T1, T2, T3 e T4, 47 (94\%), 15 (75\%), 23 $(72 \%)$ e $16(94 \%)$ foram classificados como viáveis (excelentes, bons e regulares) e 46 $(92 \%), 15(75 \%), 19(59 \%)$ e $15(88 \%)$ foram classificados como embriões excelentes e bons, respectivamente. Essas variáveis apresentaram comportamento quadrático em função do nível de uréia na dieta. Conforme a derivação das equações, o menor número e a menor percentagem de embriões viáveis, quatro embriões e $72,5 \%$, ocorreram com o consumo de $1,2 \%$ e $1,1 \%$ de uréia na MS da dieta, respectivamente (Fig. 1 e 2). O menor número e a menor percentagem de embriões excelentes e bons, 3,4 embriões e 63,0\%, coincidiram com o consumo de $1,2 \%$ de uréia na MS da dieta (Fig. 3 e 4).

Em ovelhas, McEvoy et al. (1997) observaram que o fornecimento de $30 \mathrm{~g}$ de uréia/dia reduziu a percentagem de embriões viáveis, comparado ao fornecimento de $15 \mathrm{~g}$ de uréia/dia. Segundo Dawuda et al. (2002), o efeito prejudicial da utilização de uréia na dieta sobre a qualidade embrionária pode estar relacionado ao período de seu fornecimento, visto que, a suplementação com $250 \mathrm{~g}$ de uréia/vaca/dia, durante sete dias, reduziu a percentagem de embriões viáveis, comparado à suplementação por 17 dias.

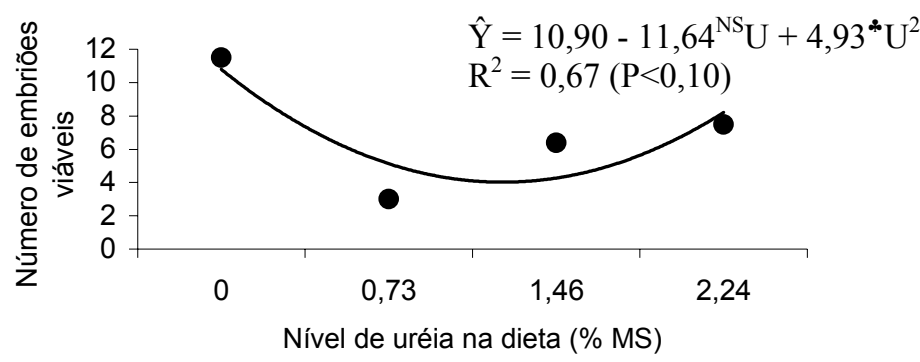

Figura 1. Número de embriões viáveis coletados de cabras da raça Alpina que consumiram dietas com diferentes níveis de uréia.

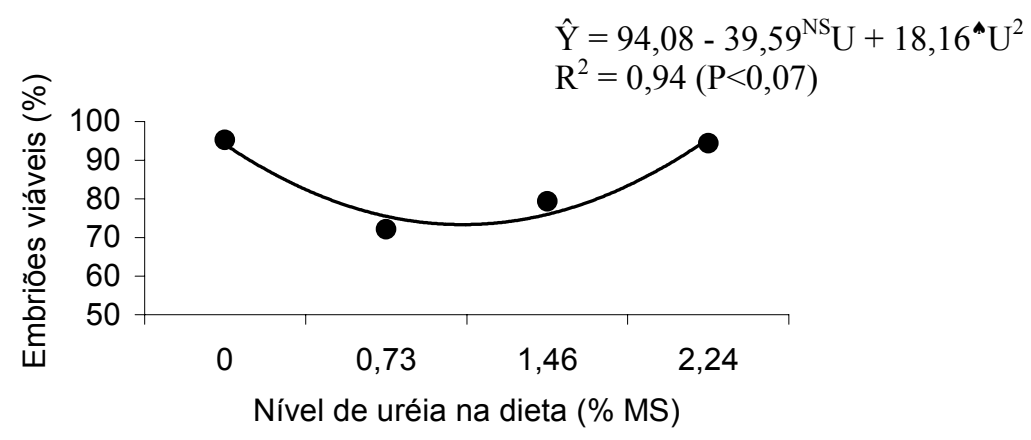

Figura 2. Percentagem de embriões viáveis coletados de cabras da raça Alpina que consumiram dietas com diferentes níveis de uréia. 


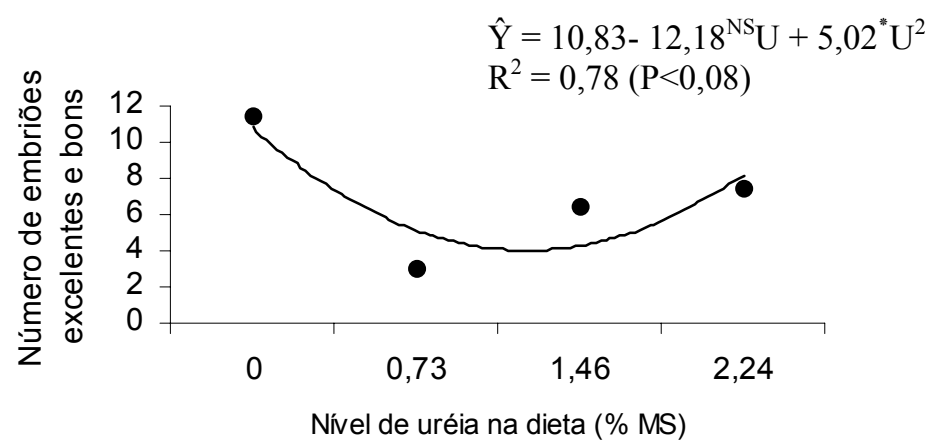

Figura 3. Número de embriões excelentes e bons coletados de cabras da raça Alpina que consumiram dietas com diferentes níveis de uréia.

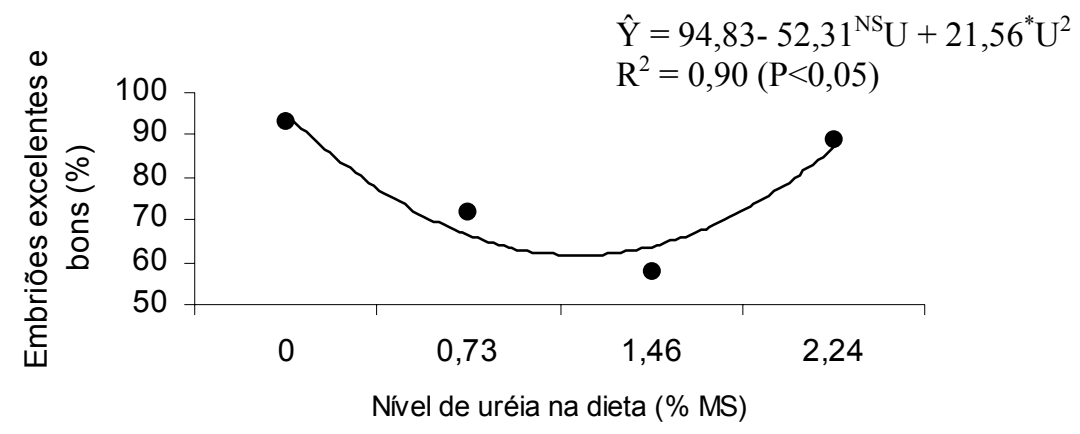

Figura 4. Percentagem de embriões excelentes e bons coletados de cabras da raça Alpina que consumiram dietas com diferentes níveis de uréia.

Ocon e Hansen (2003) verificaram que a maturação de ovócitos bovinos em meios contendo $0 ; 5 ; 7,5 ;$ e $10 \mathrm{mmols} / 1$ de uréia, equivalente a $0 ; 14 ; 21$; e $28 \mathrm{mg} / \mathrm{dl}$ de $\mathrm{N}$-uréico plasmático, respectivamente, não influenciou a taxa de clivagem no terceiro dia após a fertilização. Todavia, reduzida proporção de ovócitos maturados em meios com 7,5mmols/1 de uréia desenvolveu-se em blastocistos no oitavo dia de cultivo in vitro. Segundo os autores, a alta concentração de uréia $(>7,5 \mathrm{mmols} / \mathrm{l})$ pode desencadear algum mecanismo compensatório no ovócito que aumenta sua resistência à toxicidade, como, por exemplo, alterações no transporte de uréia pela membrana, inibindo a sua entrada na célula ou aumentando sua remoção do citoplasma. Embora tenha sido demonstrado que o transporte de uréia mediado por carreadores ocorre em outros tipos celulares (Hisanaga et al., 1991, citados por Ocon e Hansen, 2003), o sistema de transporte de uréia no ovócito, bem como sua regulação, ainda não são conhecidos.
Em relação ao estádio de desenvolvimento, foram coletados $1(0,84 \%)$ embrião de quatro células, $25 \quad(21,0 \%)$ mórulas, $18 \quad(15,1 \%)$ blastocistos iniciais, $22(18,5 \%)$ blastocistos, 28 $(23,5 \%)$ blastocistos expandidos, $13 \quad(10,9 \%)$ blastocistos eclodidos e $12(10,1 \%)$ embriões degenerados. $\mathrm{O}$ número e a percentagem de embriões coletados em cada estádio de desenvolvimento, em cada tratamento, são apresentados na Tab. 6.

Segundo Baril et al. (1993), citados por Gordon (1997), no sétimo dia após o início do estro, são coletados embriões principalmente no estádio de mórula compacta a blastocisto expandido e no oitavo dia podem ser coletados embriões nos estádios de blastocistos expandidos e eclodidos. Além disso, pode haver variação no estádio de desenvolvimento embrionário entre cabras submetidas à coleta no mesmo intervalo após o estro, bem como entre os embriões coletados de uma mesma cabra. 
Tabela 6. Número e percentagem de embriões coletados em cada estádio de desenvolvimento, em função do nível de uréia na dieta (\% MS)

\begin{tabular}{|c|c|c|c|c|}
\hline \multirow[b]{2}{*}{ Estádio de desenvolvimento } & \multicolumn{4}{|c|}{ Nível de uréia na dieta (\% MS) } \\
\hline & $\begin{array}{c}0 \\
(n=4)\end{array}$ & $\begin{array}{c}0,73 \\
(\mathrm{n}=5)\end{array}$ & $\begin{array}{c}1,46 \\
(\mathrm{n}=3)\end{array}$ & $\begin{array}{c}2,24 \\
(n=2)\end{array}$ \\
\hline Quatro células & $1(2 \%)$ & 0 & 0 & 0 \\
\hline Mórula & $9(18 \%)$ & $7(35 \%)$ & $8(25 \%)$ & $1(6 \%)$ \\
\hline Blastocisto inicial & $12(24 \%)$ & $3(15 \%)$ & $2(6,25 \%)$ & $1(6 \%)$ \\
\hline Blastocisto & $12(24 \%)$ & $1(5 \%)$ & $9(28 \%)$ & 0 \\
\hline Blastocisto expandido & $14(28 \%)$ & $4(20 \%)$ & $5(15,5 \%)$ & $5(29 \%)$ \\
\hline Blastocisto eclodido & $2(4 \%)$ & 0 & $2(6,25 \%)$ & $9(53 \%)$ \\
\hline Degenerado & 0 & $5(25 \%)$ & $6(19 \%)$ & $1(6 \%)$ \\
\hline
\end{tabular}

Valores entre parênteses $=$ número de cabras em cada tratamento.

A alta percentagem $(53 \%)$ de embriões no estádio de blastocisto eclodido, coletados das cabras do T4, pode ser sugestivo de que o excesso de uréia na alimentação teve algum efeito estimulatório sobre o desenvolvimento embrionário. McEvoy et al. (1997) observaram que os embriões coletados de ovelhas que receberam $30 \mathrm{~g}$ de uréia $/ \mathrm{kg}$ de alimento estavam em estado mais avançado de desenvolvimento do que os coletados de ovelhas que consumiram $2,5 \mathrm{~g}$ de uréia/kg de alimento.

Os teores de uréia e glicose no plasma, no dia do estro e no dia da coleta de embriões, antes da alimentação e quatro horas após, em função do nível de uréia nas dietas, são apresentados na Tab. 7.

Tabela 7. Teores de uréia e glicose no plasma, antes e quatro horas após a alimentação, nos dias do estro e da coleta de embriões, em função do nível de uréia na dieta (\% MS), coeficientes de variação (CV) e nível de probabilidade dos efeitos linear (L) e quadrático (Q)

\begin{tabular}{|c|c|c|c|c|c|c|c|}
\hline & \multicolumn{4}{|c|}{ Nível de uréia na dieta (\% MS) } & \multirow{2}{*}{$\begin{array}{l}\text { CV } \\
(\%)\end{array}$} & \multicolumn{2}{|c|}{ Valor de $\mathrm{P}$} \\
\hline & $0 \%$ & $0,73 \%$ & $1,46 \%$ & $2,24 \%$ & & $\mathrm{~L}$ & Q \\
\hline $\mathrm{UME}^{1}$ & $35,00 \pm 4,54$ & $34,80 \pm 7,98$ & $37,00 \pm 19,80$ & $37,50 \pm 4,95$ & 25 & $\mathrm{~ns}$ & ns \\
\hline $\mathrm{UTE}^{1}$ & $44,25 \pm 9,74$ & $41,00 \pm 17,96$ & $45,50 \pm 16,26$ & $52,00 \pm 24,04$ & 36 & $\mathrm{~ns}$ & ns \\
\hline $\mathrm{UMC}^{1}$ & $41,75 \pm 13,22$ & $34,80 \pm 9,01$ & $34,67 \pm 12,66$ & $49,50 \pm 14,85$ & 30 & $\mathrm{~ns}$ & ns \\
\hline $\mathrm{UTC}^{1}$ & $49,50 \pm 9,54$ & $41,80 \pm 8,07$ & $54,33 \pm 24,00$ & $49,50 \pm 4,95$ & 27 & $\mathrm{~ns}$ & ns \\
\hline $\mathrm{GME}^{1}$ & $69,00 \pm 5,35$ & $78,40 \pm 5,73$ & $78,00 \pm 0,00$ & $79,00 \pm 0,00$ & 6 & * & ns \\
\hline $\mathrm{GTE}^{1}$ & $68,00 \pm 8,90$ & $68,80 \pm 21,54$ & $83,00 \pm 9,90$ & $77,00 \pm 8,48$ & 22 & ns & ns \\
\hline $\mathrm{GMC}^{1}$ & $70,25 \pm 5,68$ & $67,00 \pm 4,18$ & $69,67 \pm 4,16$ & $68,00 \pm 8,48$ & 8 & $\mathrm{~ns}$ & ns \\
\hline GTC $^{1}$ & $80,50 \pm 6,14$ & $82,00 \pm 10,44$ & $78,67 \pm 11,50$ & $95,00 \pm 24,04$ & 14 & ns & ns \\
\hline
\end{tabular}

mg/dl. MS: matéria seca.

ns: não-significativo; ${ }^{*} \mathrm{P}<0,05$.

UME: teor de uréia no plasma antes da alimentação no dia do estro, UTE: teor de uréia no plasma 4 horas após a alimentação no dia do estro, UMC: teor de uréia no plasma antes da alimentação no dia da coleta de embriões, UTC: teor de uréia no plasma 4 horas após a alimentação no dia da coleta de embriões, GME: teor de glicose no plasma antes da alimentação no dia do estro, GTE: teor de glicose no plasma 4 horas após a alimentação no dia do estro, GMC: teor de glicose no plasma antes da alimentação no dia da coleta de embriões, GTC: teor de glicose no plasma 4 horas após a alimentação no dia da coleta de embriões.

O teor de uréia no plasma no dia do estro e no da coleta de embriões, antes da alimentação e quatro horas após, não foi influenciado $(\mathrm{P}>0,05)$ pelos tratamentos. Oliveira (2001), ao utilizar as mesmas fontes de PDR (farelo de soja) e NNP (uréia) deste estudo e níveis semelhantes de uréia $(0 \% ; 0,7 \% ; 1,4 \%$; e $2,1 \%$ na MS da dieta), também não verificou diferença no teor de uréia no plasma de vacas lactantes, em função da dieta oferecida, o que pode estar relacionado à alta degradabilidade ruminal da fonte protéica utilizada nos concentrados. Outra possibilidade é que os animais tenham se adaptado ao alto nível de uréia na dieta, devido às alterações na atividade dos microrganismos ruminais $\mathrm{e}$ também à maior concentração das enzimas 
hepáticas relacionadas ao ciclo da uréia (Payne e Morris, 1969, citados por Jordan et al., 1983). Embora o comportamento ingestivo não tenha sido avaliado, é provável que as cabras que receberam uréia nas dietas aumentaram sua freqüência de alimentação, ingerindo pequenas porções do alimento por vez, o que resultou no teor plasmático de uréia semelhante ao das cabras do grupocontrole. Por outro lado, a composição percentual das dietas experimentais pode estar relacionada à similaridade observada no teor plasmático de uréia entre cabras dos diferentes tratamentos. $\mathrm{O}$ amido proveniente do fubá de milho, ausente na dieta oferecida às cabras do $\mathrm{T} 1$, mas presente em quantidades crescentes nas dietas oferecidas à cabras dos T2 (10,1\%), T3 (16,7\%) e T4 $(23,6 \%)$, serviu como fonte de carboidratos prontamente fermentáveis, permitindo a conversão adequada do NNP proveniente da uréia em proteína microbiana.

Em estudos com novilhas (Gath et al., 1999; Kenny et al., 2002), com vacas lactantes (Dawuda et al., 2002), com ovelhas (McEvoy et al., 1997; Fahey et al., 2001) e com cabras (Fernandez et al., 1997), o fornecimento de uréia nas dietas resultou em aumento do teor sistêmico desse metabólito.

O teor de glicose no plasma antes da alimentação, no dia do estro, aumentou linearmente com o aumento do nível de uréia nas dietas $(\hat{\mathrm{Y}}=71,82+$ $\left.4,38 \mathrm{U} ; \mathrm{R}^{2}=0,59 ; \mathrm{P}<0,05\right)$. No entanto, o teor desse metabólito após a alimentação não diferiu $(\mathrm{P}>0,05)$ entre os tratamentos. No dia da coleta de embriões, o teor de glicose plasmática, antes da alimentação e quatro horas após, não diferiu $(\mathrm{P}>0,05)$ entre os animais dos tratamentos. Também Fernandez et al. (1997) não verificaram diferenças nos teores de glicose no plasma de cabras Alpinas suplementadas com 1,4\%; $1,8 \%$; e 2,9\% de uréia na MS da dieta. Em novilhas, Kenny et al. (2002) relataram que o teor sistêmico de glicose não foi influenciado pelo consumo de uréia ( 0 ou $240 \mathrm{~g} / \mathrm{dia}$ ), assim como não foi relacionada à sobrevivência embrionária no $40^{\circ}$ dia de gestação. Da mesma forma, neste estudo o teor plasmático de glicose não apresentou correlação $(\mathrm{P}>0,05)$ com o número de estruturas $\mathrm{e}$ de embriões coletados ou com a qualidade embrionária.

\section{CONCLUSÕES}

A uréia pode ser fornecida no nível de 2,24\% na MS da dieta de cabras não lactantes, sem que haja redução no desempenho dos animais, no número e na qualidade dos embriões coletados.

\section{REFERÊNCIAS BIBLIOGRÁFICAS}

BARIL, G.; BREBION, P.; CHESNE, P. (Eds). Manuel de formation pratique pour la transplantation embryonnaire chez la brebis et la chevre. Roma: FAO (Publication 115), 1993. 183p.

BARIL, G.; CASAMITJANA, P.; PERRIN, J. et al. Embryo production, freezing and transfer in Angora, Alpine and Saanen goats. In: MEETING EUROPEAN EMBRYO TRANSFER ASSOCIATION, 4., 1988. Lion. Proceeding... Lion, 1988. p.67-93.

BISHONGA, C.; ROBINSON, J.J.; McEVOY, T.G. et al. The effects of excess rumen degradable protein in ewes on ovulation rate, fertilization and embryo survival in vivo and during in vitro culture. Anim. Prod., v.58, p.447, 1994. (Abstract).

BLANCHARD, T.; FERGUSON, J.; LOVE, L. et al. Effect of dietary crude-protein type on fertilization and embryo quality in dairy cattle. Am. J. Vet. Res., v.51, p.905-908, 1990.

CANFIELD, R.W.; SNIFFEN, C.J.; BUTLER, W.R. Effects of excess degradable protein on postpartum reproduction and energy balance in dairy cattle. $J$. Dairy Sci., v.73, p.2342-2349, 1990.

DAWUDA, P.M.; SCARAMUZZI, R.J.; LEESE, H.J. et al. Effect of timing of urea feeding on the yield and quality of embryos in lactating dairy cows. Theriogenology, v.58, p.1443-1455, 2002.

ELROD, C.C.; BUTLER, W.R. Reduction of fertility and alteration of uterine $\mathrm{pH}$ in heifers fed excess ruminally degradable protein. J. Anim. Sci., v.71, p.694-701, 1993.

ELROD, C.C.; VAN AMBURGH, M.; BUTLER, W.R. Alterations of $\mathrm{pH}$ in response to increased dietary protein in cattle are unique to the uterus. $J$. Anim. Sci., v.71, p.702-706, 1993.

FAHEY, J.; BOLAND, M.P.; O'CALLAGHAN, D. The effects of dietary urea on embryo development in superovulated donor ewes and on early embryo survival and development in recipient ewes. Anim. Sci., v.72, p.395-400, 2001.

FERNANDEZ, J.M.; SAHLU, T.; LU, C.D. et al. Production and metabolic aspects of nonprotein nitrogen incorporation in lactation rations of dairy goats. Small Rum. Res., v.26, p.105-117, 1997.

GATH, V.; LONERGAN, P.; BOLAND, M.P. et al. Effects of diet type on establishment of pregnancy and embryo development in beef heifers. Theriogenology, v.51, p.224, 1999 (Abstract).

GORDON, I. Embryo transfer and associated techniques in goats. In: Controlled reproduction in sheep and goats. Cambridge, UK: University Press, 1997, v.2, p.416-439. 
GUSMÃO, A.L.; MOURA, J.C.A.; CHALHOUB, M. et al. Colheita, avaliação e criopreservação de embriões caprinos. Rev. Bras. Reprod. Anim., v.27, p.115-120, 2003

HISANAGA, H.; IIOKA, H.; MORIYAMA, I. et al. The mechanism of human placental urea transport: a study using placental brusch border (microvillous) membrane vesicles. Asia Oceania J. Obstet. Gynaecol., v.17, p.67-72, 1991.

JORDAN, E.R.; CHAPMAN, T.E.; HOLTAN, D.W. et al. Relationship of dietary crude protein to composition of uterine secretions and blood in highproducing postpartum dairy cows. J. Dairy Sci., v.66, p.1854-1862, 1983.

JORDAN, E.R.; SWANSON, L. V. Effect of crude protein on reproductive efficiency, serum total protein, and albumin in the high-producing dairy cows. $J$. Dairy Sci., v.62, p.58-63, 1979.

KENNY, D.A.; BOLAND, M.P.; DISKIN, M.G. et al. Effect of rumen degradable protein with or without fermentable carbohydrate supplementation on blood metabolites and embryo survival in cattle. Anim. Sci., v.74, p.529-537, 2002.

LIMA-VERDE, J.B.; LOPES JÚNIOR, E.S.; TEIXEIRA, D.I.A. et al. Colheita de embriões pela técnica trans-cervical em cabras da raça Saanen criadas nos trópicos. Rev. Bras. Reprod. Anim., v.27, p.489-490, 2003.

McEVOY, T.G.; ROBINSON, J.J.; AITKEN, R.P. et al. Dietary excesses of urea influence the viability and metabolism of preimplantation sheep embryos and may affect fetal growth among survivors. Anim. Reprod. Sci., v.47, p.71-90, 1997.

NUTRIENT requirements of goats: Angora, dairy, and meat goats in temperate and tropical countries. Washington, D.C.: National Academy, 1981. 91p

OCON, O.M.; HANSEN, P.J. Disruption of bovine oocytes and preimplantation embryos by urea and acidic pH. J. Dairy Sci., v.86, p.1194-1200, 2003.
OLIVEIRA, M.M.N.F. Uréia para vacas leiteiras no pós-parto: dinâmica folicular e características reprodutivas. 2001. 93f. Tese (Doutorado) Universidade Federal de Viçosa, Viçosa, MG.

PAPADOPOULOS, S.; LONERGAN, P.; GATH, V. et al. Effect of diet quantity and urea supplementation on oocyte and embryo quality in sheep. Theriogenology, v.55, p.1059-1069, 2001.

PAYNE, E.; MORRIS, J.G. The effect of protein content of the diet on the rate of urea formation in sheep liver. Biochem. J., v. 113, p. 659, 1969.

SALLES, H.O.; ANDRIOLI, A.; SIMPLÍCIO, A.A. et al. Manual de transferência de embriões em caprinos. Sobral: Embrapa Caprinos, 2002. 64p. (Embrapa Caprinos, Documentos, 40).

SALLES, H.O. Circuito fechado para a colheita de embriões em caprinos. Disponível em: http://www.cnpc.embrapa.br/topicos/capaartigos/artig o11.htm. Acessado em: 12 nov. 2003.

SILVA, D.J.; QUEIROZ, A.C. Análise de alimentos: métodos químicos e biológicos. 3.ed. Viçosa, MG: UFV, 2002. 235p

SINCLAIR, K.D.; KURAN, M.; GEBBIE, F.E. et al. Nitrogen metabolism and fertility in cattle: II. Development of oocytes recovered from heifers offered diets differing in their rate of nitrogen release in the rumen. J. Anim. Sci., v.78, p.2670-2680, 2000.

STRINGFELLOW, D.A.; SEIDEL, S.M. Manual da Sociedade Internacional de Transferência de Embriões. 3.ed. Illinois: International Embryo Transfer Society, 1999. 180p.

SISTEMA de análises estatísticas e genéticas. Versão 8.0. Viçosa: UFV, 1997. 150p.

WHITTINGHAM, D. G. Survival of mouse embryos after freezing and thawing. Nature, v.233, p.125, 1971. 